\title{
Design of a Post-Disaster Temporary Living Space Through the Use of Shape Evolution
}

\section{SIGRADI2018 TECHNOPOLITICAS \\ xxii congresso da sociedade iberoamericana de gráfica digital 22th conference of the iberoamerican society of digital graphics 07|08|09|novembro|2018 iau usp | são carlos | sp br}

\author{
Füsun Cemre Karaoglan \\ Istanbul Technical University, Architectural Design Computing Graduate Program | Turkey | \\ cemrekaraoglan@gmail.com \\ Sema Alaçam \\ Istanbul Technical University, Faculty of Architecture | Turkey | alacams@itu.edu.tr
}

\begin{abstract}
As the increasing number of disasters taking place each year result in a larger number of people in need of urgent sheltering, temporary shelters become a more critical subject of architectural design. With this in mind, the aim of this study is to design a temporary postdisaster living space for the displaced people. Towards this aim, 2D layout possibilities are generated and evaluated with genetic algorithms. Different from the previous studies, the project focuses on the potential use of shape evolution and multi-objective genetic algorithms for the design of a disaster relief shelter. The results are expected to produce a holistic digital model that can respond to different post-disaster scenarios.
\end{abstract}

Keywords Computational design; Emergency architecture; Genetic algorithms; Modularity; Mass customization.

\section{INTRODUCTION}

Sheltering is one of the most crucial needs of humanity and every year many people are displaced due to various reasons such as "natural disasters, famine, development and economic changes." (O'Keefe, 2017). In a report that bases its research upon displaced people, it is stated that "Since 2008, an average of 26.4 million people per year have been displaced from their homes by disasters brought on by natural hazards. This is the equivalent to one person being displaced every second." (IDMC \& NRC, 2015). Therefore, this project focuses on designing a temporary living space that can respond to the needs of different post-disaster scenarios and form a modular system through differentiation of units. When designing temporary shelters, it is a necessity to deal with the provision of materials, low-cost production and the time limit in the emergency as well as the needs of the users and the qualities of the space. Although computational approaches might lead much more efficient and optimal design solutions, they have been utilized in very few examples. For that reason in this thesis, computational tools are used throughout the design process. The study aims to produce a holistic digital model that contains all the steps from the conceptual design to production. Shape evolution shapes the core of the methodology of the study, where a shape is firstly generated through rules and then it is evaluated using genetic algorithms. In that scope, a 2D layout that serves as a base for geometrical relationships is generated through an algorithmic approach. The generated layout contains all the modular settlement possibilities of the rule-based system. Then, these possibilities are evaluated with multi-objective genetic algorithms by defining the requirements of disaster relief shelters. Multi-objective genetic algorithms are suitable for solving architectural design problems, especially when the case is post-disaster construction, as they are specialized in optimizing contradicting objectives. The struggle to define intangible architectural concepts for the evaluation of possible settlement scenarios holds potential for the further use of genetic algorithms for architectural problems. Different from the previous studies, this paper aims to focus on the design of a temporary shelter that can respond to different user types and disaster scenarios through mass customization, using an alternative methodology. While serving as a temporary space, the design outcomes are expected to be able to create a pattern of customized units that was lacking in the previous built examples.

\section{DISASTER RELIEF SETTLEMENTS \\ MAJOR PROBLEMS IN DISASTER RELIEF SETTLEMENTS}

Most often shelters have to respond to a sudden increase in demand thus putting the provision of materials, low-cost production and the time limit in the emergency in front of the architectural quality (Abulnour, 2014). The built examples mostly consist of repetitive units without any differentiation from one another. As a result, many people from many different social attributes and backgrounds are compelled to dwell in identical spaces. When considering that shelters are built temporarily, usually for short periods, this problem might seem to be insignificant. However, in some cases where the provision of permanent housing is challenging, temporary shelters are used for a much longer time than they are supposed to. For instance, in one of the previous examples, shelters that were designed to serve for 1-2 years within a postdisaster rehabilitation phase were accommodated up to 30 years (Gümüş, 2000). Also, in a report, it has been stated that permanent housing reconstruction can take up 
to 5 years in certain cases (FEMA, 2005). As proven by experience, shelters may have to uphold the requirements of a permanent house and serve a purpose that it was neither designed nor appropriate for. Therefore, in the upcoming situations, it is crucial for temporary living spaces to be more flexible in terms of service periods and user types. Today, the design of a disaster relief shelter and providing a secure space through the aftermath of a catastrophe is not considered a vital issue until the disaster itself is encountered. It has been observed that in most cases that the efficiency of the designs has not reached its full potential (Bashawri, 2014). So, analyzing the previous examples is a requirement to get past the existing problems and to reach an optimized solution. In addition, it is a necessity to document the research on the matter in order to understand the position of this study within the literature.

One of the most crucial aspects that shelters lack is the ability to be customized according to varying types of residents. Almost all of the built examples have been the repetition of identical units that offers no differentiation from one user to another. When the way users interact with their surroundings is observed, it can be seen clearly that identical units do not satisfy the needs of the inhabitants. In one of the research based on YeniköyKocaeli temporary settlement, it is seen that only \%19 of the residents have not made any changes in their units (Figure 1). Alterations have taken place outdoors and indoors in \%48 of the cases and they have taken place only outdoors in \%30 of the cases (Şener and Şener, 2003).
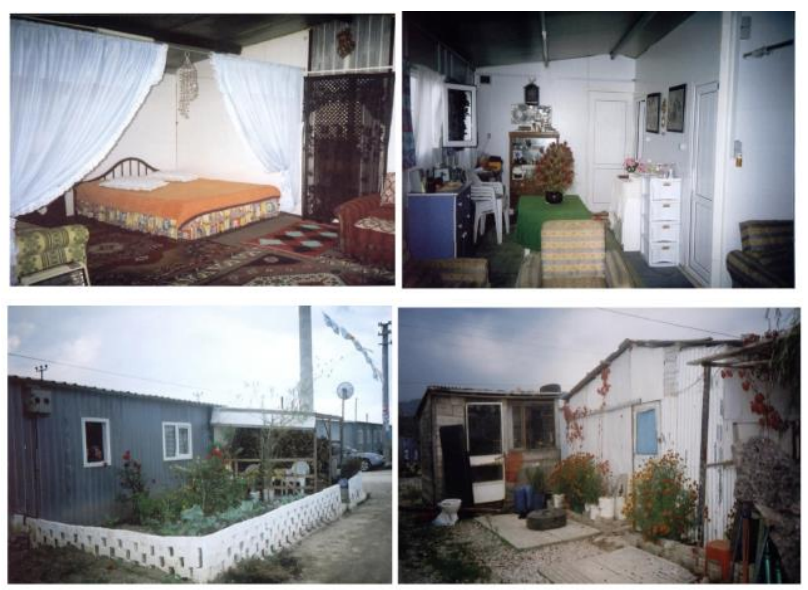

Figure 1: Changes made by the users (Şener and Altun, 2009).

This research clearly shows the significance of customization within the units and it proves the necessity of a higher quality architectural design even for temporary shelters. When displaced people are compelled to live in these settlements for several months or years, they feel the need to make modifications in and around the units. If these modifications were foreseen and the structures were flexible enough to allow participation during or after the construction process, then the architectural quality presented could have been much higher.

\section{CONCEPTS RELATED TO DISASTER RELIEF SETTLEMENTS}

When designing a shelter rather than a permanent house, architectural concepts incorporate new vocabulary as the construction phase takes place within an emergency phase. Even though the concepts are assumed to be selfexplanatory, they are defined in several different ways within the literature. In regards to that, a related terminology is discussed and their relevance to the study is clarified. House and shelter are the first two terms that need to be defined before going deeper into subcategories. One definition is that they are two parts of an ambiguous relationship where they indicate the "point of time reference in a disaster life cycle from the appearance of a threat to the return back to normal routine activities in the community." (Quarantelli, 1991). In addition, the shelter is defined as "Secure habitable covered living space providing privacy and dignity for those within it." (IFRC, 2010). Several researchers have worked on categorizing types of post-disaster settlements according to their functions and estimated periods of service. There are two major categorizations related to post-disaster living spaces. In this study, the classification of shelters presented by IFRC (2013) is chosen. It consists of 6 types (Figure 2) :

1 - Emergency Shelter: Provides life-saving support, used right after the disaster for a brief time.

2 -Temporary Shelter: Easily built, low-cost, reusable shelter types. May have a shorter span of life in order to satisfy these criteria.

3 - Transitional Shelter: Upgradable shelters in terms of construction location or materiality. Quickly built and may have to be set up by the users themselves.

4 - Progressive Shelter: Upgradable to permanent structures in terms of structural property and detailing.

5 - Core Shelter: First part of a permanent housing. Small initial solution but can grow into a bigger space.

6 - Permanent Housing: Reconstructed spaces for longterm usage.

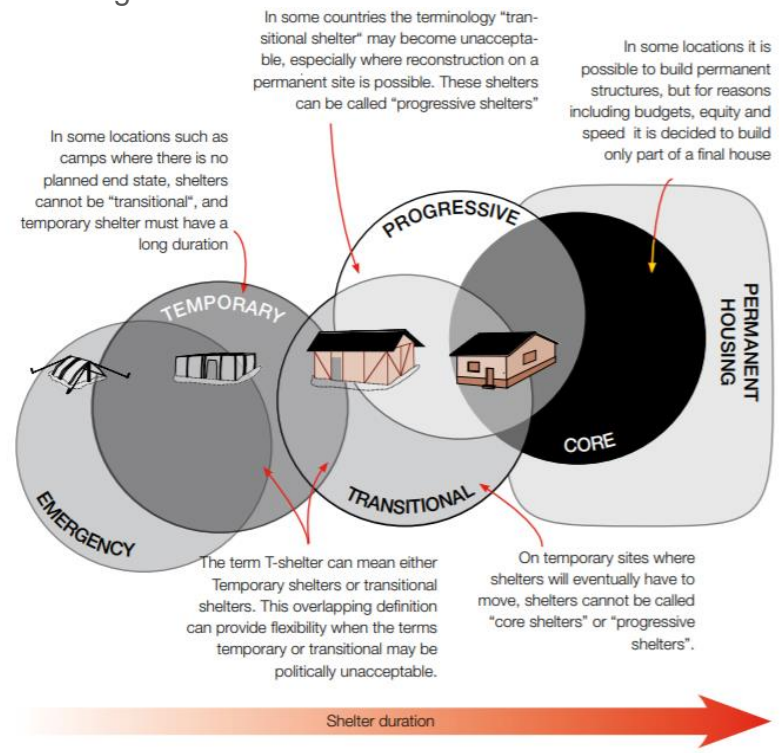

Figure 2: Overlapping stages of post-disaster relief structures (IFRC, 2013).

In this study, the living space is expected to have a transformable character in order to be able to adapt to the changing periods of service. Because, one of the biggest 
problems in post-disaster settlements in developing countries is the lack of sustainable solutions where a temporary shelter can be transformed into a more transitional or progressive one in time (Limoncu and Bayülgen, 2008). Therefore, the shelter to be designed in this study is expected to start to function as a temporary shelter and change itself through materiality and size to become a transitional shelter. So, the living space to be designed can be classified as a T-shelter, which is defined as the general term referring to both temporary and transitional shelters (IFRC, 2013).

\section{PREVIOUS EXAMPLES ON DISASTER RELIEF UNIT DESIGN}

One of the previous examples that focus on designing a temporary shelter is named Mob-ARCH and it follows a methodological architectural design approach (Şener and Altun, 2009) (Figure 3). It strives to underline the needs of the users and find solutions for the points that were lacking in the built examples. In that sense, MobARCH has a similar approach to this study as it also sets its design goals and evaluation criteria from the very beginning. It achieves the objectives related to detail design, reusability and small footprint, but it has limited potential in creating customization according to different users. When these units grow into a neighborhood size, the composition tends to be the whole made up of repetitive units.

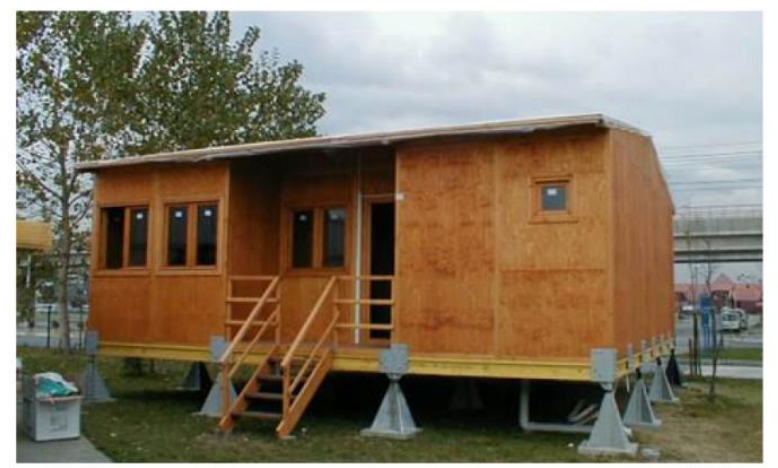

Figure 3: 1:1 Prototype of Mob-ARCH (Şener and Altun, 2009).

Another example named Ski Shelter utilizes used disposable skis as the structural support material for a tent (Figure 4). Even though the result is not very appropriate for long-term use and user alterations, reusing such an efficient and strong material for a completely different function offers a new perspective (Salvalai et al., 2017).
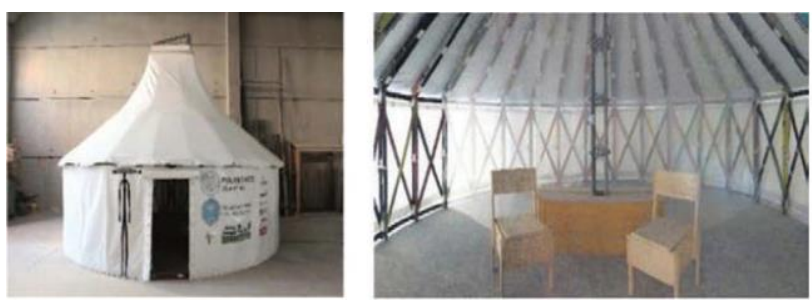

Figure 4: 1:1 Prototype of Ski Shelter (Salvalai, 2017).

In an emergency, it is expected for a structure to be assembled in very short time and with limited external help (IFRC, 2013). Therefore, the inhabitants should be able to construct the whole structure by themselves without the help of a technical authority or assembly tools. The main problem with these examples is that they are designed, manufactured and assembled manually which causes the whole process to be inadequate under postdisaster conditions. For instance, the Ski Shelter is constructed within 4 working days in a real-life scenario (Salvalai et al., 2017) which may not be fast enough to respond to urgent sheltering needs of hundreds of displaced people. It could have been much more efficient if it could be designed, produced and built through an automated process. As post-disaster construction is a multi-layered problem with several contradicting parameters to satisfy, the aid of a computational tool can help the process to be much faster and optimized.

\section{COMPUTATIONAL DESIGN APPROACHES IN POST-DISASTER SETTLEMENTS}

Computational approaches might lead much more efficient and optimal design solutions when a post-disaster scenario is in the center of the question. "Since digital tools hold potential for simplification, standardization and modularization, they can be applied to this humanitarian design problem to achieve a better performance and mass-customization." (Rezoug, 2013). Therefore, the use of computational design in solving the two of the major problems listed in the previous section is going to be further discussed. The use of mass customization and modularity through parametric tools aims to enlighten the methods that can solve the lack of differentiation in disaster relief settlements. In addition, the possibilities that automated production presents is going to be exemplified as opposing to the costs of manual production economically and time-wise.

\section{MASS CUSTOMIZATION MODELS}

Mass customization models have been utilized by many different researchers in order to create differentiating outcomes from a single model. Through small alterations in parameters, many different options can easily be manufactured. When the case is a post-disaster situation, these models can be very efficient as they are a solution to settlements made up of identical units.

The first step in constructing these models is determining the parameters and their corresponding entities. In one of the previous studies, the requirements play an important role in defining the parameters. The parameters are not just classified as physical but also contextual and climatic ones in order to be able to further deepen the architectural characteristics of the outcomes. Especially the struggle to approach the contextual parameters within the frame of the cultural traits of the displaced population and to define intangible concepts through measurable characteristics is a struggle very similar to the one in the evaluation phase of this study (Daher et al., 2015) (Figure 5).

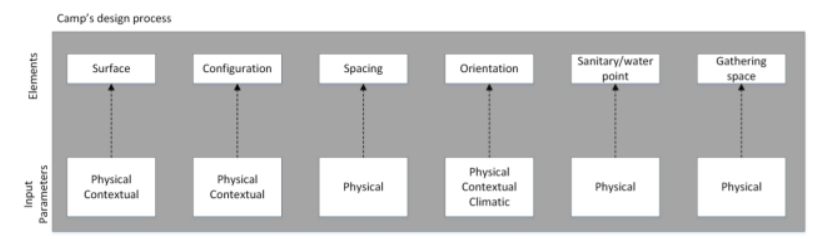

Figure 5: Parameters and the correlating entities-camp site (Daher et al., 2015).

Another example that utilizes computational tools for parametrization of units within a post-disaster settlement 
is based on the parametric modeling of a prefabricated temporary housing unit. The researcher determines the requirements of a temporary housing unit through the analysis of previous examples and then quantifies them to use as parameters for differentiation of the units in the next step (Rezoug, 2013). The study also aims to overcome the problem of repetition and the use of identical units in the post-disaster settlements. It achieves that by designing a model that can change its size, detailing, morphology and materiality according to different scenarios (Figure 6). Although the struggle to create modular units that can differentiate according to different users is similar to this thesis, the methodologies differ.

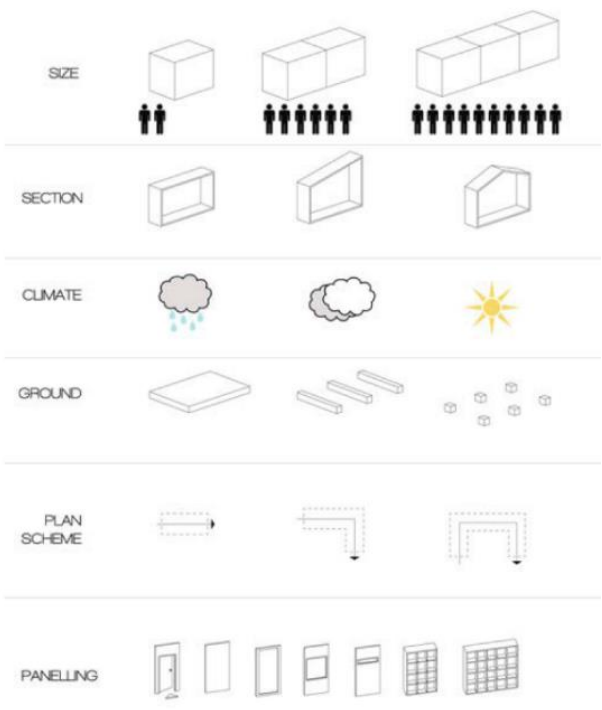

Figure 6: Parameters of the prefabricated units (Rezoug, 2013).

Another research that uses parametric design as a tool for creating differentiation and customization amongst the post-disaster settlement, achieves this objective through the use of container units. The study is based on the works produced as the outcomes of a computational design studio that puts post-disaster shelter design in the center of the question (Torus and Şener, 2015). Especially the design named CPoDs (Container PostDisaster Shelters) which is made up of containers of different sizes is selected to be further developed (Figure 7). An interface gives the opportunity to change the parameters such as the number of users and users or the size of the settlement area and different arrangements are obtained through the use of generative algorithms (Şener and Torus, 2009).

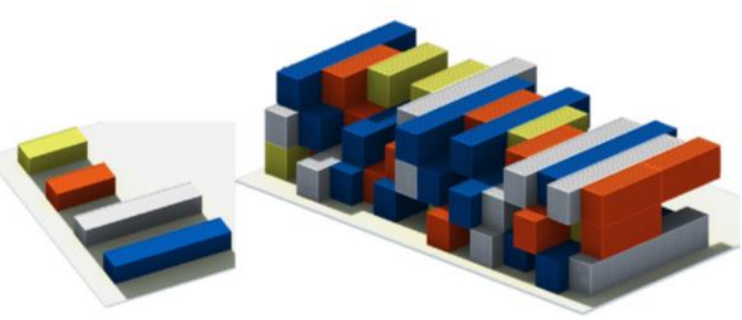

Figure 7: Types of containers of different sizes (Torus and Şener, 2015).

Temporary settlements have to challenge the limitations of cost when creating architectural quality. The same goes for social housing. In social housing examples, affordability is usually put in front of architectural quality. Most of the built complexes from the modernism period have later faced many problems related to their inhabitants and proven themselves to be problematic in social aspects. However, a study has managed to present a good solution to this matter. By putting mass customization in focus and utilizing computational tools in the preconstruction period, they have managed to achieve architectural quality within a social housing complex. As a part of the research, the repetition patterns that constitute the grammar of Malagueira Houses of Siza are deciphered to form a set of rules. The algorithm that is made up of these rules, is utilized to design the units of the social housing complex. In this way, the future inhabitants were able to create a customized version of their unit through an interface where they type their preferences (Duarte, 2005) (Figure 8). This example has presented the potential of the computation in design, especially in the mass customization of social houses where it is not possible to achieve through traditional architectural design methods. However, when the construction takes place in a post-disaster situation, it is not possible for users to define their needs and preferences due to the urgent need of sheltering. The way to achieve this can be by categorizing the families in terms of the number of members and creating different arrangements of modules. Therefore, the users can set up the modular units towards their wishes in the designated area.

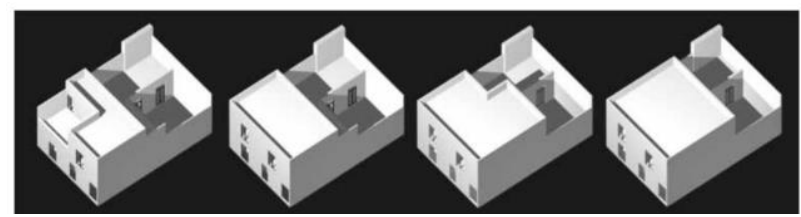

Figure 8: Four different backyard house alternatives (Duarte, 2005).

\section{DIGITAL FABRICATION TOOLS}

Until the permanent housing is provided, modular construction for the temporary settlements can make a significant difference in terms of time and efficiency (Gunawardena et al., 2014). Automated production is an inseparable part of the modular construction and through the use of prefabricated modules, the settlements can be established in very short times. Especially the utilization of digital fabrication tools can serve as an important element in designing a holistic digital model which contains all the steps from the conceptual design to the construction.
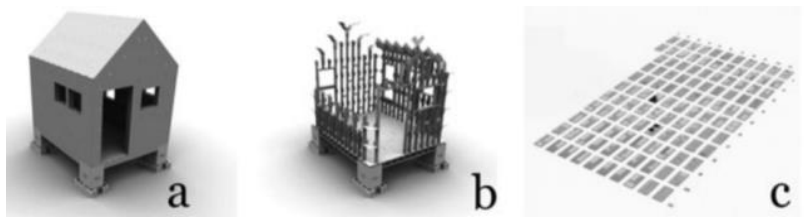

Figure 9: Initial model (a), Fabrication simulation (b), Sheets to be cut by CNC (c) houses (Sass and Botha, 2006).

One of the best examples demonstrating the efficient use of digital fabrication is the Instant House. It is focused on the use of a system that can translate the components of a digital model into a production manual houses (Sass and Botha, 2006) (Figure 9 and 10). It aims for the fabrication of building elements on site through the use of digital tools and presents an option where the users can 
manufacture and build their own houses (Sass and Botha, 2006). The case of Instant House shows a great example of the holistic approach towards architectural design and fabrication. Its methodology can serve as a solid base for the fabrication phase of the current study

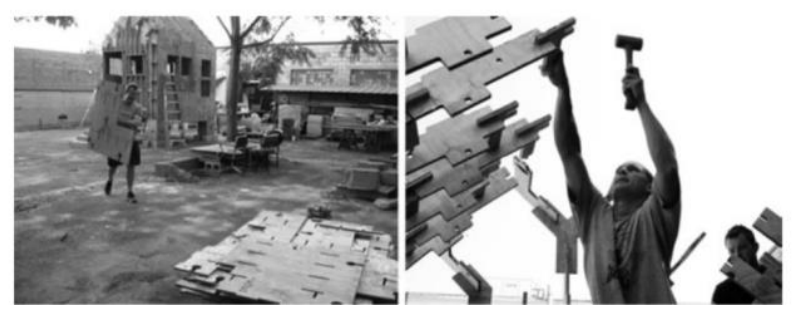

Figure 10: Lightweight pieces, easy to carry and assemble (Sass and Botha, 2006).

\section{SHAPE GRAMMARS}

Shape grammars are the recursive application of certain rules on an initial shape and it is a term first introduced by Stiny (1980). Through this rule-based process, the initial shape grows into another form. In one of the studies, these shape grammars have been used to define a "Shelter Grammar" (Gonçalves, 2014) (Figure 11). These recursive rules have been implemented as a decisionmaking tool in designing the plan schemes of shelters.

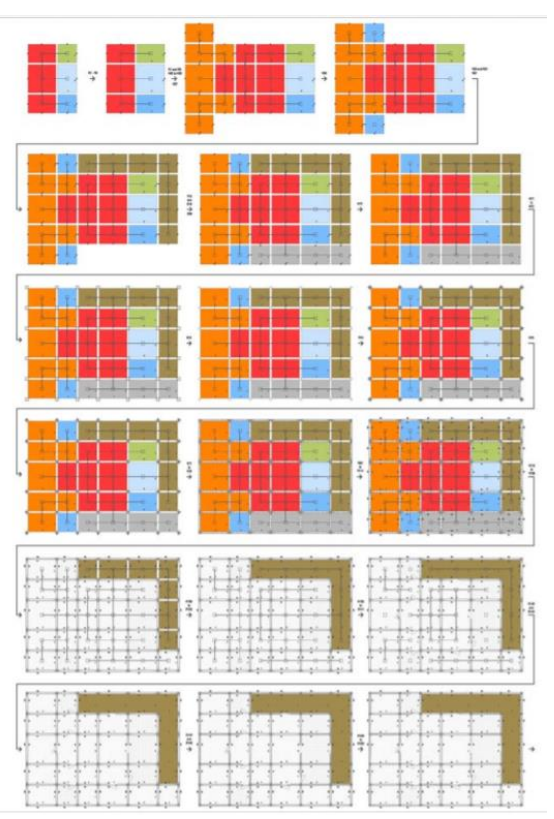

Figure 11: A part of the plan layout generation process (Gonçavles, 2014).

The building elements are all added one by one according to the defined relationships making it possible to have different plan layouts for a shelter settlement (Gonçalves, 2014). Applying the shape grammars to the production of plan layouts for shelters can serve as a quick solution as a conceptual design tool. Also, the first section of this thesis where a 2D layout is generated through certain rules resembles the methodology carried out in "Shelter Grammar". However, in this study, the shelter layouts generated are evaluated with the aid of genetic algorithms, shifting the focus of methodology on shape evolution.

\section{SHAPE EVOLUTION}

Chouchoulas (2003) defines shape evolution as "An algorithmic method for conceptual architectural design combining shape grammars and genetic algorithms". So, shape evolution is a two-step process where a rule-based shape is evaluated and evolved through the genetic algorithms. The genetic algorithms use the rules of the shape grammar as a genotype, changing them to reach the objectives of the project. It aims to serve as a tool in the conceptual phase of architectural design, as it can answer to the objectives of an architectural project in the design language of a certain architect. Firstly, the basic rules that form the shape grammar are determined, which are only three in the case study by Chouchoulas (2003) (Figure 12). Then, through the use of genetic algorithms, outcomes of the rules are evaluated and then altered according to its proximity to the fitness functions. The outcomes that scored the maximum are presented (Figure 13). Another research also bases its focus on shape evolution and uses the interface in the previous study to produce architectural designs (Badem, 2007). Defining a set of rules for the creation of the shape and testing the possible outcomes through genetic algorithms sets the summary of the methodology of the current study. However, in this thesis, the parameters to be changed or in other words the genotype is not the rules generating the rule-based layout but the variations of the possible layouts.

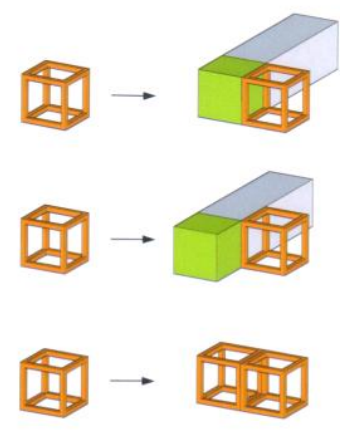

Figure 12: Three main rules (Choucoulas, 2003).

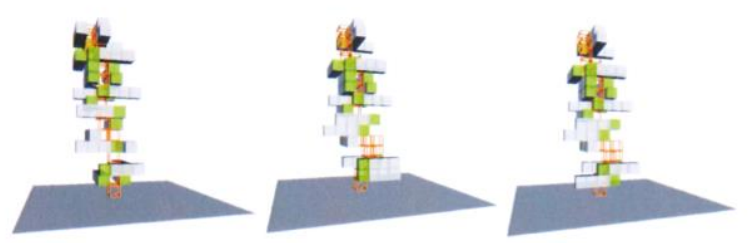

Figure 13: Tower designs with maximum scores (Choucoulas, 2003).

\section{FORM GENERATION EXPERIMENTS}

This study is focused on designing a temporary living space that can respond to the needs of different postdisaster scenarios and form a modular system through differentiation of units. Towards this aim, firstly an algorithm that defines the combination logic of the units is required to be constructed. Then, this algorithm is coded in Processing in order to produce all the possible solutions. The outcomes of the algorithmic system are evaluated through the genetic algorithms in Grasshopper according to the fitness functions that focus post-disaster construction requirements (Figure 14). 


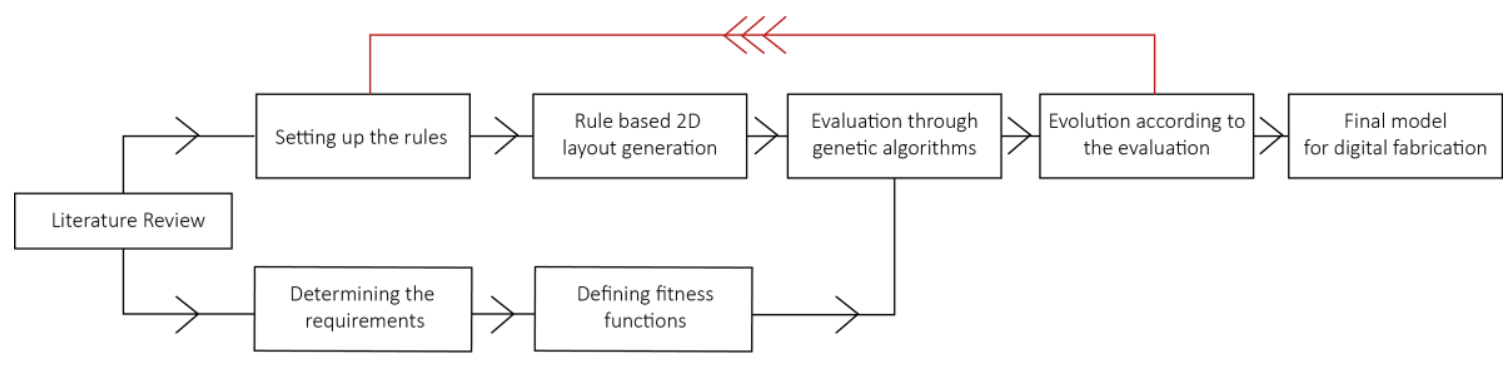

Figure 14: The steps of the study.

\section{INITIAL ASSUMPTIONS AND MODULARITY}

In this sense, firstly a set of rules that define the combination of units are determined. These rules are the base of the algorithm that sets the logic behind the growth pattern of the settlement. Through the application of these rules, the living space grows box by box, forming a modular pattern as a result. The modules forming this pattern are made up of $3^{*} 3^{*} 3 \mathrm{~m}$ boxes and they are categorized according to their functions. Towards this aim, four different modules with four different functions are defined (Figure 15) :

A: Shared wet space ( 1 box / Floor Area: $\left.3^{\star} 3=9 \mathrm{~m}^{2}\right)$ : A wet space used by two families for hygienic purposes.

B: Living space $\left(2\right.$ boxes $\left./ 3^{*} 6=18 \mathrm{~m}^{2}\right)$ : The common area where families use for daily activities. It also includes space for cooking.

C: Personal space ( 1 box / Floor Area: $\left.3^{*} 3=9 \mathrm{~m}^{2}\right)$ : It is the space where members of the family can sleep or store their belongings. Every family has maximum two personal space modules.

D: Open areas / courtyard ( 4 boxes / Floor Area: $6^{*} 6=36$ $\left.\mathrm{m}^{2}\right)$ : The area connecting different modules. It serves as a shared courtyard thus enhancing the neighborhood pattern and social integration within the community.

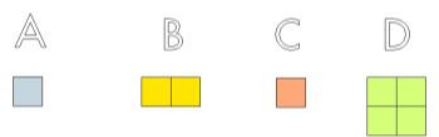

Figure 15: Different types of modules made up of boxes.

Firstly, a module of wet space sets the basis for the growth pattern. In each step, another box is added according to the rules. The basic rules that constitute the algorithm are:

All the boxes connect to each other from the center of their edges. This way the construction phase is simplified and openings between different units do not present any problems.

- $\quad$ A wet space is shared by two living spaces. Therefore two modules of $B$ connects to $A$.

- $\quad$ A living space has maximum two personal spaces, so every $\mathrm{B}$ module can accommodate two $\mathrm{C}$ modules at most.

In order to test and solidify the algorithm, the combination possibilities in each step are listed manually. In the first step, a living space is connected to a wet space, which can also be named as the sum of $A$ and $B$ modules: $A+B$ (Figure 16). In the second step, a second living space is connected to the wet space module. Even without moving further into different modules, the number of the outcomes reaches large numbers, thus proving the suitability of the algorithm for the presented design problem and presenting more options for genetic algorithms to test. In order to be able to list all the options, a table that intersects the geometry from the previous step and the binding logic of $A+B$ has been shown (Figure 17). On the third step, the personal spaces are added to one chosen combination from the previous step as it is challenging to list all the possible outcomes manually (Figure 18).

\section{A1 A2 A3 AS A5 A6 A7 A8 A9 A10 All A12

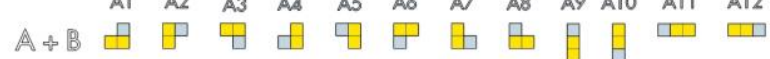

Figure 16: 12 possible outcomes of the combination of $A$ and $B$.

\begin{tabular}{|c|c|c|c|c|c|c|c|c|c|c|c|c|}
\hline 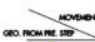 & & $P_{2}$ & 中 & - & 田。 & 巴 & 月 & . & 目, & 目 10 & (ه⿴囗十" & m $m$ m \\
\hline & Aी & & 田 & 由 & 田 & $\mathbb{8}$ & B & & & 目 & \begin{tabular}{|l|} 
षा \\
\end{tabular} & 田 \\
\hline IP & A2 & & 崮 & $\oplus$ & 田 & 岸 & & 由 & 甲 & 8 & 再 & \\
\hline 甲 N & A & $甲$ & & $\boxplus$ & का & & & 出 & 苜 & & 由 & 田 \\
\hline$\oplus^{\oplus \mu}$ & $\wedge \oplus$ & $\boxplus$ & 田 & & & & 田 & 由 & 申 & 间 & & (1) \\
\hline प्र $\mathrm{As}$ & NS & 田 & क्ष & & & 电 & 再 & & 亩 & 目 & & 四 \\
\hline$\nabla \alpha$ & $\begin{array}{lll}A S & \text { 甲 }\end{array}$ & 甲 & & & 田 & & $\boxplus$ & 届 & 西 & & \begin{tabular}{|l|} 
田 \\
\end{tabular} & 田 \\
\hline B $N$ & \begin{tabular}{l|l}
$N$ & B
\end{tabular} & & & 田 & 由 & $\boxplus$ & & क & को & 田 & | & \\
\hline$B A$ & & 田 & 果 & 由 & & 进 & क & & & 目 & $\boxplus$ & 帛 \\
\hline 目 $A$ & & 甲 & 目 & 田 & 田 & 罒 & 百 & & & 臬 & 䀟 & 四 \\
\hline 1 1010 & 10 目 & 早 & & 由 & 星 & & 由 & 且 & 目 & & \begin{tabular}{|l|l|} 
目 \\
\end{tabular} & 且 \\
\hline DDall & "1口 & סקי & 母. & & & 田 & m & $\boxplus$ & 四 & 目 & & m \\
\hline DI: & $12 \boxplus$ & & 田 & ست⿴囗十 & 口田 & $\boxplus$ & & 曲 & 四 & 田 & س & \\
\hline
\end{tabular}

Figure 17: Possible outcomes of the combination of a wet space with two living spaces.

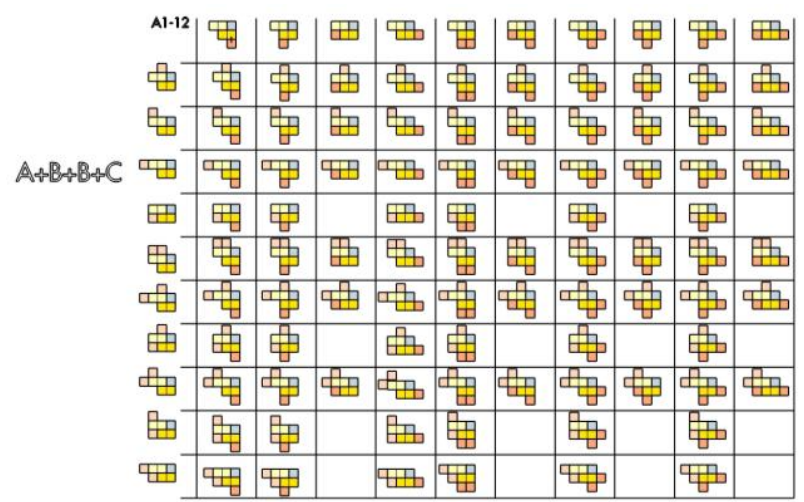

Figure 18: The possible outcomes of the combination of a selected $A+B+B$ and $C$ modules.

\section{D LAYOUT GENERATION}

As it is not possible to list and evaluate all the possible combinations manually, the algorithm is coded into Processing. The code is based on the formation of a matrix that symbolizes the boxes. Every different unit with a separate function is represented by different numbers. Also, in order for the code to distinguish the modules serving two different families, they are numbered separately. For example, the first living space is marked 
as "2" on the matrix whereas the second living space to be added is marked as " 3 " (Figure 19).

The same logic in the previous section applies to the flow of the code. Firstly, a wet space marked as " 1 " is placed in the center of the matrix. Then, every cell in the matrix is checked. If the cell is marked as " 1 ", then the code checks the neighboring cells excluding the diagonal ones.

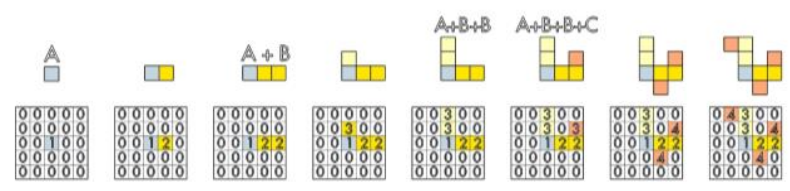

Figure 19: The matrix that represents the growth of the boxes.

The reason for that is the rule described in the previous section which compels the boxes to connect only through the middle of their edges. The neighbor to be used for the next step is chosen randomly and the same "if"-"then" construction allows the matrix to grow. The rule-based pattern produces all the possible combinations made up of $A, B, C$ and $D$ units. The data documenting the outcomes are then transferred to Rhino/Grasshopper in order to be evaluated by genetic algorithms.

\section{EVOLUTION AND EVALUATION}

After producing all the possible combinations, this geometrical data is transferred into Grasshopper. This data enables Grasshopper to visualize geometrical properties of all the combinations one by one through the use of a list. In this way, every alternative can be evaluated by genetic algorithms according to several different objectives. Since the disaster relief living space is expected to satisfy various competing objectives, multiobjective genetic algorithms are utilized in the evaluation phase. The Galapagos add-on of Grasshopper allows implementation of multiple objectives and adjustment of the weights of the different fitness functions. Firstly, these fitness functions have to be defined in order to be able to evaluate the imported geometries through genetic algorithms. Some of these objectives are intangible concepts thus making the evaluation process through quantifiable elements difficult. It is challenging to determine one single correct definition of these concepts but it is possible to define them through the use of an intuitive understanding and knowledge of architecture. The objectives are defined under 4 main groups: Performance,
Production/Transportation/Construction, Quality (Figure 20).

Performance: The objectives related to performance compete to achieve a better indoor environment through optimizing the orientation of the settlement according to sunlight hours in different seasons, minimizing thermal losses and maximizing daylighting conditions at the same time.

Flexibility/Adaptability: The ability to respond to different types of disaster scenarios and topographies is an important aspect of creating a flexible design. With each geography and catastrophe, the priorities of a shelter change thus altering the objectives as well. In response to that, the coefficients that prioritize some fitness functions amongst others are going to change according to different scenarios. Objectives related to performance are more important for a post-disaster shelter set up in a cold climate, whereas flexibility comes across as the most crucial objective for a shelter set up in a developing country for an indeterminate period.

Ease of Production/Transportation/Construction: The dimensions of the pieces of the structure are expected to be minimized in order to be able to fit a larger number of modules within a vehicle or a storage unit. Also, smaller pieces can enable the users to transport and construct the modules without external help.

Architectural Quality: Objectives related to architectural quality come across as the most challenging ones to define in a quantifiable manner. Therefore, "the contextual parameters" (Daher et al., 2012) that have been mentioned in the previous chapters are going to set a basis for the definitions of the architectural quality objectives in this study. In that scope, mobility nodes and visual connections within the modules are going to be investigated. Also, the layouts are going to be expected to have maximum number of modules within an area alongside the maximum amount of open areas, which are in this case $\mathrm{D}$ modules.

\section{SELECTION AND FEEDBACK}

As $2 \mathrm{D}$ layout generation is still in progress, an initial trial with genetic algorithms is conducted amongst four manually produced modules and two fitness functions. The objectives are chosen to be towards performance as it is possible to define the requirements easily.

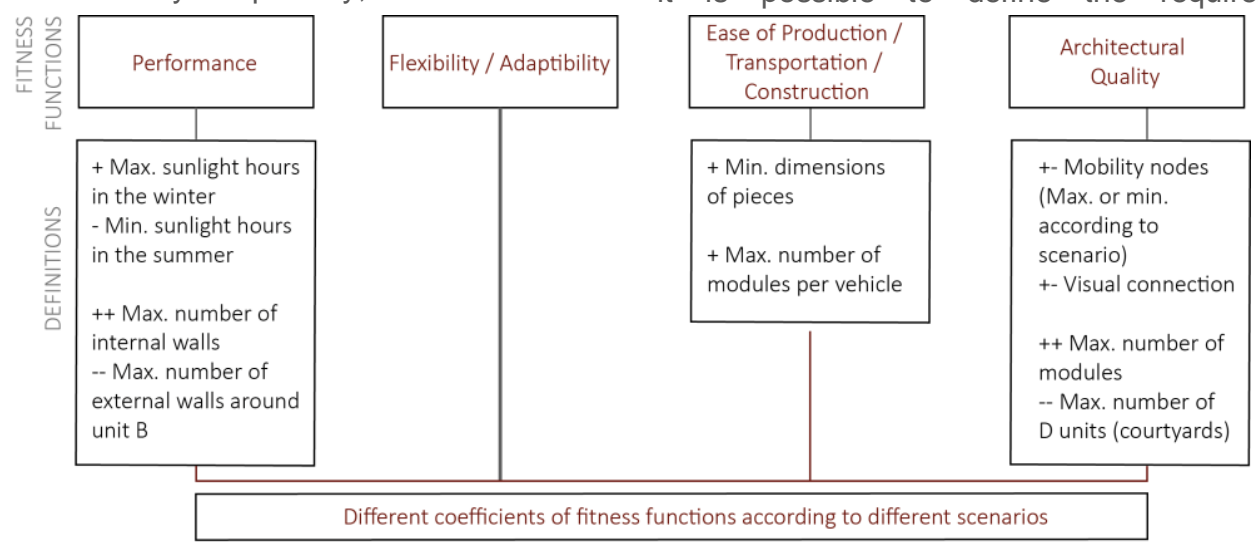

Figure 20: Fitness functions for the evaluation and their definitions. 
Throughout the evaluation process Ladybug plugin of Grasshopper has been utilized. Firstly, four different possible module types made up of $A, B$ and $C$ units are manually produced. Then, a solid is extruded from their boundaries in order to be able to conduct the sunlight hours analysis on the exterior vertical envelope. The genetic algorithms are expected to find the orientation in which sunlight hours are maximized in the winter and minimized in the summer. By rotating the solid 360 degrees and testing four different combinations, genetic algorithms aim to find several optimized results.

As a result of the optimization process, the first module is rotated 306 degrees from the north and the objectives are reached on the 4th generation. It presented itself to be the best solution for winter and summer sunlight hours objectives. The analysis for both winter and summer sunlight hours is documented on the selected and rotated modules.

\section{CONCLUSION}

As the application process is still in progress, the results of the study are not yet clear. There are several further improvements that are aimed to be achieved in the next step of the study. First of all, the evolutionary role of genetic algorithms in shape evolution has not yet been used in its full potential. The rules setting up the $2 \mathrm{D}$ layout is expected to be altered and evolved by the genetic algorithms in the course of evaluating the outcomes according to the defined objectives. Secondly, it is a necessity to strengthen the connection between the observations in the previous post-disaster settlement examples and their effects on the reasoning of the 2D layout generation. Third and finally, the evaluation criteria that set up the basis for the objectives need to be defined more clearly and again in connection to the previous sections. On the other hand, computational design has proven itself to have a strong potential, especially when the case is post-disaster settlements as it is a crucial tool in creating modularity, mass customization and automated fabrication. Therefore, this thesis holds the potential to present a holistic digital model which can result in a design fulfilling the requirements of a post-disaster living space.

\section{REFERENCES}

Badem, Y. (2007). Genetik Algoritmaların Yaratıcı Mimari Tasarımda Kullanımı (Doctoral dissertation). Istanbul Teknik Üniversitesi, Fen Bilimleri Enstitüsü, ISTANBUL.

Bashawri, A., Garrity, S., \& Moodley, K. (2014). An overview of the design of disaster relief shelters. Procedia Economics and Finance, 18, 924-931.

Chouchoulas, O. (2003). Shape evolution: an algorithmic method for conceptual architectural design combining shape grammars and genetic algorithms (Doctoral dissertation). University of Bath, BATH.

Daher, E., Kubicki, S., \& Halin, G. (2015). A Parametric Process for Shelters and Refugees' Camps Design. In Martens, B, Wurzer, G, Grasl T, Lorenz, WE and Schaffranek, R (Eds.), Real Time - Proceedings of the 33rd eCAADe Conference - (Vol. 2, pp. 541-548). Retrieved from http://papers.cumincad.org/cgibin/works/Show?_id=ecaade2015_92
Duarte, J. P. (2005). Towards the mass customization of housing: the grammar of Siza's houses at Malagueira. Environment and planning B: Planning and Design, 32(3), 347-380.

FEMA, (2005). Planning for Post Disaster Recovery and Reconstruction, Washington D.C., FEMA (Federal Emergency Management Agency).

Gonçalves, A. (2014). A Grammar for Shelters. An exploration of rulebased designs in prefabricated and modular shelters'. Proceedings of the 32th International eCAADe, 327-336.

Gunawardena, T., Ngo, T., Mendis, P., Aye, L., \& Crawford, R. (2014). Time-Efficient Post-Disaster Housing Reconstruction with Prefabricated Modular Structures. open house international, 39(3), 59.

Gümüş, K. (2000). Afet Konutları ve Ürün Geliştirme Sorunu. Domus, 4 (36).

IDMC \& NRC (2015). Global Estimates 2015, People Displaced by Disasters. Geneva, Switzerland.

IFRC (2010). IFRC shelter kit guidelines. Switzerland: International Federation of Red Cross and Red Crescent Societies.

IFRC/RCS (2013). Post-disaster shelter: Ten designs. Geneva: International Federation of Red Cross and Red Crescent Societies.

Limoncu, S., \& Bayülgen, C. (2008). Türkiye'de Afet Sonrası Yaşanan Barınma Sorunları. Megaron, 3(1).

O'Keefe, E. (2017). Displaced Person/Displacement. Retrieved April 24, 2018 from http://www.unesco.org/new/en/socialand-human-sciences/themes/internationalmigration/glossary/displaced-person-displacement/

Rezoug, A. (2013). Hızlı, Ucuz Ve Uyarlanabilir: Afet Sonrası Geçici Konut Tasarımı İçin Dijital Bir Model (Doctoral dissertation). Istanbul Teknik Üniversitesi, Fen Bilimleri Enstitüsü, ISTANBUL.

Salvalai, G., Imperadori, M., Lumina, F., Mutti, E., \& Polese, I. (2017). Architecture for refugees, resilience shelter project: A case study using recycled skis. Procedia engineering, 180, 1110-1120.

Sass, L., \& Botha, M. (2006). The instant house: a model of design production with digital fabrication. International Journal of Architectural Computing, 4(4), 109-123.

Stiny, G. 1980, 'Introduction to shape and shape grammars', Environment and Planning B: Planning and Design, 7, 343351.

Şener, S. M., \& Altun, M. C. (2009). Design of a post disaster temporary shelter unit. A| Z ITU Journal of the Faculty of Architecture, 6(2), 58-72.

Şener, S.M., \& Şener, E. (2003). Architectural Design Computing Studio Works on Prefabricated Post-Disaster Housing. Werner Fischer \& Federico Fluckiger (Eds.), 32nd International Symposium:Information-CommunicationKnowledge-Engineering Education Today, 331-334.

Şener, S. M., and Torus, B. (2009). Container Post-Disaster Shelters - C-PoDS: A Generative Approach to Temporary Post-Disaster Sheltering, Proceedings of 27th eCAADe Conference, 599-604.

Quarantelli, E. L. (1991). Patterns of sheltering and housing in American disasters. University of Delaware, Disaster Research Center.

Torus, B., \& Şener, S. M. (2015). Post-disaster shelter design and CPoDS. A| Z ITU Journal of the Faculty of Architecture, $12(1)$, 